\title{
Medical Case Report on Repeat Treatment of Restless Legs Syndrome with Intravenous Infusion of Iron
}

\author{
Katherine Condon James Chipman \\ Stanton Consultancy, Cornwall, UK
}

\author{
Keywords \\ Restless legs syndrome $\cdot$ Iron $\cdot$ Ferric carboxymaltose $\cdot$ Ferritin
}

\begin{abstract}
Restless legs syndrome (RLS) is a debilitating neurological disorder for which a range of medical interventions with varied efficacy has been employed. Based on evidence of iron deficiency in the substantia nigra of the midbrain, there are reports of substantial benefits from intravenous iron infusion. This case report demonstrates a strong statistically significant negative correlation between serum ferritin and RLS severity of symptoms in a subject with RLS who received 2 intravenous infusions of ferric carboxymaltose over a period of 464 days. The results provide further evidence to support the treatment strategy.
\end{abstract}

(C) 2021 The Author(s).

Published by S. Karger AG, Basel

\section{Introduction}

Restless legs syndrome (RLS; also known as Willis-Ekbom disease) is a disorder of the nervous system that affects up to $10 \%$ of the population and is manifested as unpleasant sensations, discomfort and a powerful urge for movement which significantly impacts on quality of life [1-4] Although predominantly the legs are affected, other areas such as the arms and torso may also be affected. Medication to relieve symptoms includes dopamine agonists, dopaminergic agents, benzodiazepines as relaxants, opiates, and anticonvulsants [5-7].

The aetiology of the disorder is not clear [8] although there appears to be a genetic component to susceptibility [9]. Evidence indicates that low concentrations of iron in the brain (specifically in the substantia nigra region of the brain) contribute to the disorder in some individuals $[10,11]$. Indeed the strongest environmental factor that relates to RLS is iron deficiency $(<50 \mu \mathrm{g} / \mathrm{L}$ plasma ferritin; [12]). Several studies have shown an inverse relationship between serum ferritin levels and severity of RLS $[13,14]$. However, the relationship

\section{Karger!}


is complicated since patients with normal peripheral iron stores can have a relatively low brain iron concentration compared to control subjects $[15,16]$. There is also an apparent link between a SNCA-Rep1 polymorphism which correlates with susceptibility and iron deficiency in RLS [17].

Since the substantia nigra is involved in the regulation of dopamine in the body, a linkage between iron deficiency and effectiveness of dopamine in treatment is evident. Indeed changes in dopamine may be secondary to iron deficiency $[18,19]$.

It is not surprising therefore that iron therapy has been considered and trialled for RLS (for review see Allen et al. [3]). These authors note that intravenous infusion of 1,000 $\mathrm{mg}$ iron was effective if the serum ferritin level was $<300 \mu \mathrm{g} / \mathrm{L}$ and transferrin saturation $<45 \%$ and recommend such treatment. There is clear evidence that intravenous ferric carboxymaltose shows improvement of RLS $[20,21]$. In particular, 2 randomized, double-blind, placebocontrolled clinical studies using 1,000 mg of ferric carboxymaltose versus placebo have shown that RLS patients who received the iron had significantly greater improvement in RLS symptoms [22, 23]. Park et al. [24] recently concluded that the lower the transferrin saturation \% then the greater the response to intravenous iron treatment. This study reports the response of a subject with RLS to intravenous iron treatment and shows the relationship between severity measures and serum ferritin concentrations over a period of 2 years and repeated iron infusions.

\section{Materials and Methods}

The subject was female white Caucasian and aged 64-65 during the period of assessment and treatment at The Royal Cornwall Hospital, Treliske, Cornwall, UK. RLS had onset at the age of 35. Treatment had been Tramadol (50 mg, as necessary) and dietary manipulation including ferrous sulphate $200 \mathrm{mg}$ daily up to age 50), dopamine agonists and dopaminergic agents (eventual augmentation), and benzodiazepines (age 50-60). Since age 60 and up to and including the period of the study treatment were: buprenorphine $(5 \mathrm{mg}$ slow release patch), Tramadol (100 mg daily) and ferrous sulphate (200 mg daily). To determine the possibility of an associated peripheral neuropathy, a full neurological clinical examination was carried out and showed no abnormalities. In addition, results of nerve conduction studies and electromyography conducted at the Nuffield Health Exeter Hospital (UK) were entirely normal indicating no evidence of peripheral neuropathy.

In a pilot treatment (detailed results not shown), this patient received a single iv infusion of $1,000 \mathrm{mg}$ of ferric carboxymaltose having a prior serum ferritin level of $40 \mu \mathrm{g} / \mathrm{L}$ and an average weekly RLS severity score of 32 based on IRLS (see below). The ferritin concentration was elevated to $443 \mu \mathrm{g} / \mathrm{L}$ at 6 weeks after iron infusion and the RLS severity scores were reduced to a range of between 8 and 20 for a monitoring period of 25 days commencing only 2 days after the iron infusion. There was therefore sufficient evidence of beneficial effect to warrant the present continuation study at the initiation of which, the serum ferritin level was $195 \mu \mathrm{g} / \mathrm{L}$.

Infusions of ferric carboxymaltose were administered intravenously to the subject at a dosage of $500 \mathrm{mg}$ and at the times indicated in Figure 1. There were no symptoms to suggest any adverse effects of the iron infusions. Severity of RLS was measured over a period of 464 days. The assessment of severity necessarily involved a daily self-assessment of symptoms over each $24 \mathrm{~h}$ period. The assessment was based on the International Restless Legs Scale (IRLS) as one of several assessment methods discussed and employed by Kohnen et al. [25]. The assessment was modified to relate to each day of the study rather than based on the average of a week so as to be more informative. Such information is complemented with the timing and dosage of iron infusion and periodic measurements of serum ferritin concentra-

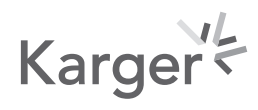




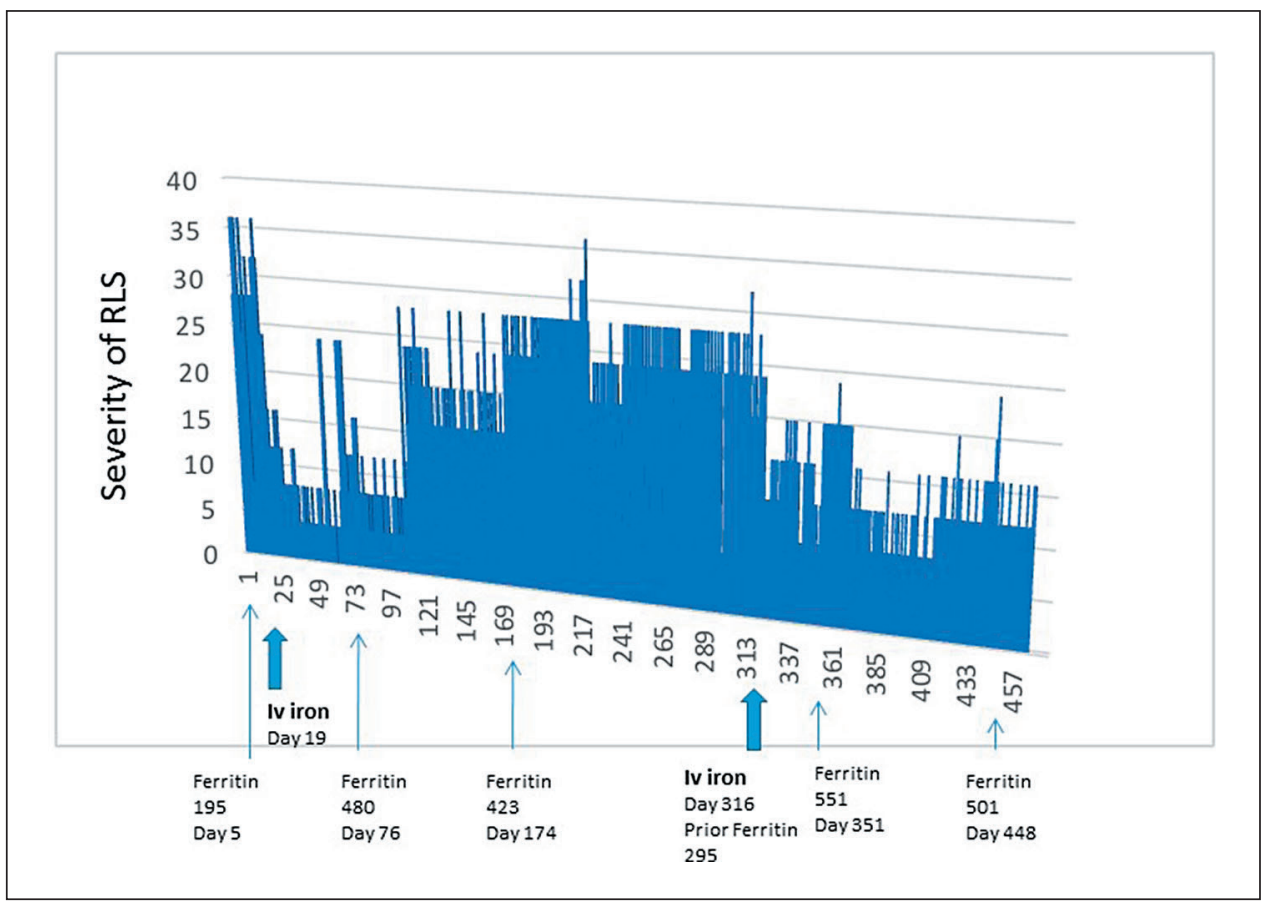

Fig. 1. Values show the daily RLS severity scores over the period of 464 days of assessment. Bold arrows show the timing of each of 2 intravenous infusions of ferric carboxymaltose $(500 \mathrm{mg}$ ). Narrow arrows show the timing of measurement and measured value of serum ferritin. RLS, restless legs syndrome.

tions so as to seek potential associations. Data are shown in Figure 1. The severity scores range from 0 to 40 .

\section{Results of the Case}

Although none of the iron infusions had completely removed symptoms, there was a clear reduction of severity of symptoms after each infusion. Severity then gradually worsened again with time. The delay period between iron infusion and reduction of severity of symptoms varied. The general trend was for a decrease of severity following the first iron infusion (Day 19) followed by increased severity starting at day 101 . The subsequent (second) iron infusion on day 316 led to a rapid further reduction of severity up to the end of the study on day 464 . There was a statistically significant negative correlation between serum ferritin level and the average daily severity scores (compiled from 5 daily scores centred on the day of ferritin measurement) (Pearson correlation coefficient $[r]=-0.945, p<0.01$ ).

\section{Discussion and Conclusion}

This case report study can only be seen as indicative of a benefit of iron infusion in a single individual but adds to the expanding evidence for such benefit. Although difficult to be precise in determining the serum ferritin level that offers reduced severity in this study, it appears that a beneficial serum ferritin level in this subject needs to be maintained within the 450-550 $\mathrm{\mu g} / \mathrm{L}$ range. The results justify a continued effort to test and optimise the treatment in a larger number of subjects. Such studies would benefit from 
more objective measurements of severity and more extensive measurements particularly of serum iron levels, Total Iron Binding Capacity, transferrin saturation $\%$ and Herceptin concentrations.

In considering the safety aspects of iron infusion, it is important to avoid iron overload. Elevations of serum ferritin in the range 300-1,000 $\mathrm{mg} / \mathrm{L}$ are normally considered a concern as a surrogate marker alert for causative conditions such as hereditary haemochromatosis, liver disease, malignancy, infection, and inflammatory conditions. However, a serum ferritin exceeding $300 \mu \mathrm{g} / \mathrm{L}$ in a subject who had deliberate iron infusion would not trigger such an alert since the cause is known. Mild elevations below 1,000 $\mu \mathrm{g} / \mathrm{L}$ are "tolerable" and in the absence of hereditary haemochromatosis, the risk of hepatic iron overload and liver toxicity is exceedingly low at this concentration [26-28]. Thus, referral to a gastroenterologist, haematologist or physician with an interest in iron overload is considered appropriate if serum ferritin is $>1,000 \mu \mathrm{g} / \mathrm{L}$ or if the cause of elevated serum ferritin is unclear. Specialist review is necessary if serum ferritin exceeds $1,000 \mu \mathrm{g} / \mathrm{L}$ due to the increased risk of fibrosis and cirrhosis above this threshold [29]. Iron infusion therapy has very minimal risk regarding hypersensitivity [30]. Evidence from epidemiology for the potential of high serum iron to cause cancer is limited. In one study, high serum iron and transferrin \% saturation was associated with an increased risk of non-skin cancers in women but not in men in which serum iron was associated with a decrease in cancer risk. There was no association of cancer risk with ferritin concentrations [31]. Serum iron $\geq 140 \mu \mathrm{g} / \mathrm{dL}$ was reported to be associated with an increased risk of liver and breast cancer although this was particularly significant when associated with lifestyle risks [32]. Importantly, the risk/benefit ratio should take into consideration that effective treatment has the possibility of reducing risk associated with alternative treatments. Ultimately a personalised regime to maintain optimal iron status in the substantia nigra region of the brain in responsive RLS subjects is required in an attempt to alleviate this debilitating disorder that affects up to $10 \%$ of the population.

\section{Statement of Ethics}

This is a case report and not a research project. Being only a report on outcome of treatment the paper is exempt from ethical committee approval. Written informed consent was obtained from the patient for publication of this Case Report.

\section{Conflict of Interest Statement}

Although the authors have an interest in benefitting patients with RLS, the authors have no conflicts of interest to disclose.

\section{Funding Sources}

The authors have no funding sources to disclose.

\section{Author Contributions}

The 2 authors made an equal contribution to the assessment of the related literature, the analysis of the data and preparation of the Case Report. 


\section{Data Availability Statement}

All data generated or analysed during this study are included in this article. Further enquiries can be directed to the corresponding author.

\section{References}

1 Connor JR, Patton SM, Oexle K, Allen RP. Iron and restless legs syndrome: treatment, genetics and pathophysiology. Sleep Med. 2017;31:61-70.

2 Earley CJ, Silber MH. Restless legs syndrome: understanding its consequences and the need for better treatment. Sleep Med. 2010;11:807-15.

3 Allen RP, Piccheitti DL, Auerbach M, Cho YW, Connor JR, Earley CJ, et al. Evidence-based and consensus clinical practice guidelines for the iron treatment of restless legs syndrome/Willis Ekbom disease in adults and children: an IRLSSG task force report. Sleep Med. 2018;41:27-44.

4 Bartl M, Trenkwalder C, Muntean ML, Sixel-Doring F. Restless-legs-syndrom: ein update. Somnologie. 2020;24: $1-13$.

5 Mackie S, Winkelman JW. Long-term treatment of restless legs syndrome (RLS): an approach to management of worsening symptoms, loss of efficacy and augmentation. CNS Drugs. 2015;29:351-7.

6 Winkelman JW, Armstrong MJ, Zesiewicz T, Allen RP, Chaudhuri KR, Ondo W, et al. Practice guideline summary: treatment of restless legs syndrome in adults. Neurology. 2016;87:2585-93.

7 Oertei WH, Trenkwalder C, Zucconi M, Benes H, Garcia-Borreguero D, Bassetti C, et al. State of the art in restless legs syndrome therapy; practice recommendations for treating restless legs syndrome. Movement disorders. Clin Pract. 2007;22(S18):S466-75.

8 Koo BB, Bagai K, Walter AS. Restless legs syndrome: current concepts about disease pathophysiology. Tremor Other Hyperkinet Mov. 2016;6:401-50.

9 Winkelmann J, Müller-Myhsok B. Genetics of restless legs syndrome: a burning urge to move. Neurology. 2008; 70:664-5.

10 Allen RP, Earley CJ. The role of iron in restless legs syndrome. Movement disorders. Mov Disord. 2007; 22(Suppl 18):S440-8.

11 Connor JR, Ponnuru P, Wang XS, Patton SM, Allen RP, Earley CJ. Profile of altered brain iron acquisition in restless legs syndrome. Brain. 2011;134:959-68.

12 Norlander NB. Therapy in restless legs. Acta Med Scand. 1953;145:453-7.

13 Sun ER, Chen CA, Ho G, Earley CJ, Allen RP. Iron and the restless legs syndrome. Sleep. 1998;21:371-7.

14 Kryger MH, Otake K, Foerster J. Low body stores of iron and restless legs syndrome: a correctable cause of insomnia in adolescents and teenagers. Sleep Med. 2002;3:127-32.

15 Earley CJ, B Barker P, Horská A, Allen RP. MRI-determined regional brain iron concentrations in early- and late-onset restless legs syndrome. Sleep Med. 2006;7:458-61.

16 Godau J, Schweitzer KJ, Liepelt I, Gerloff C, Berg D. Substantia nigra hypoechogenicity: definition and findings in restless legs syndrome. Mov Disord. 2007;22:187-92.

17 Zhu XY, Wang HM, Wu TT, Liu T, Chen YJ, Li X, et al. SNCA-Rep1 polymorphism correlates with susceptibility and iron deficiency in restless legs syndrome. Parkinsonism Relat Disord. 2020;81:12-7.

18 Erikson KM, Jones BC, Beard JL. Iron deficiency alters dopamine transporter functioning in rat striatum. J Nutr. 2000;130:2831-7.

19 Earley CJ, Connor J, Garcia-Borreguero D, Jenner P, Winkelman J, Zee PC, et al. Altered brain iron homeostasis and dopaminergic function in restless legs syndrome (Willis-Ekbom disease). Sleep Med. 2014;15: 1288-301.

20 Hornyak M, Scholz H, KiemenA, Kassubek J. Investigating the responses to intravenous iron in restless legs syndrome: an observational study. Sleep Med. 2012;13:732-5.

21 Lieske B, Becker I, Schulz RJ, Polidori MC, Kassubek J, Roehrig G. Intravenous iron administration in restless legs syndrome: an observational study in geriatric patients. Z Gerontol Geriatr. 2016;49:626-31.

22 Allen RP, Adler CH, Du W, Butcher A, Bregman DB, Earley CJ. Clinical efficacy and safety of IV ferric carboxymaltose (FCM) treatment of RLS: a multi-centred, placebo-controlled preliminary clinical trial. Sleep Med. 2011;12:906-13.

23 Cho YW, Allen RP, Earley CJ. Clinical efficacy of ferric carboxymaltose treatment in patients with restless legs syndrome. Sleep Med. 2016;25:16-23.

24 Park HR, Choi SJ, Joo EY, Allen RP. Patient characteristics predicting responses to intravenous ferric carboxymaltose treatment of restless legs syndrome. Sleep Med. 2020;75:81-7.

25 Kohnen R, Allen RP, Benes H, Garcia-Borreguero D, Hening WA, Stiasny-Kolster K, et al. Assessment of restless legs syndrome: methodological approaches for use in practice and clinical trials. Mov Disord. 2007;22(Suppl 18):S485-94.

26 Olynyk JK, Gan E, Tan T. Predicting iron overload in hyperferritinemia. Clin Gastroenterol Hepatol. 2009;7: 359-62. 
27 Allen KJ, Bertalli NA, Osborne NJ, Constantine CC, Delatycki MB, Nisselle AE, et al. HFE Cys282Tyr homozygotes with serum ferritin concentrations below 1000 microg/L are at low risk of hemochromatosis. Hepatology. 2010;52:925-33.

28 Chin J, Powell LW, Ramm LE, Ayonrinde OT, Ramm GA, Olynyk JK. Utility of hepatic or total body iron burden in the assessment of advanced hepatic fibrosis in HFE hemochromatosis. Sci Rep. 2019;9:20234

29 Goot K, Hazeldine S, Bentley P, Olynyk J, Crawford D. Elevated serum ferritin - what should GPs know? Aust Fam Physician. 2012;41:945-9.

30 Rampton D, Folkersen J, Fishbane S, Hedenus M, Howaldt S, Locatelli F, et al. Hypersensitivity reactions to intravenous iron: guidance for risk minimization and management. Haematologica. 2014;99(11):1671-6.

31 Chua AC, Knuiman MW, Trinder D, Divitini ML, Olynyk JK. Higher concentrations of serum iron and transferrin saturation but not serum ferritin are associated with cancer outcomes. Am J Clin Nutr. 2016;104:736-42.

32 Wen CP, Lee JH, Tai YP, Wen C, Wu SB, Tsai MK, et al. High serum iron is associated with increased cancer risk. Cancer Res. 2014;74(22):6589-97. 